\title{
Mass Transfer - The Skeleton of Purification Processes
}

\author{
Behnam Khoshandam \\ Semnan University \\ Iran
}

\section{Introduction}

The purification or generally separation processes play a major role in a chemical, petrochemical, oil and gas industry. After producing a synthetic material usually a purifying section should be designed. The purification processes contain broad units of absorption/ desorption, distillation, liquid-liquid extraction, leaching, humidification/dehumidification, drying, adsorption/desorption, evaporation, membrane and crystallization. Processing design of these units is one of duties of chemical engineers and for this reason literatures related to purification are taught to chemical engineers as different courses on unit operations and separation processes.

The basic rules of mass transfer are as skeleton of different separation or purification processes. Concentration gradient of one or more constituents in a media can force the molecules to transfer in different directions based on Fick's first law of diffusion. Creating a convection form in flow of molecules using different ways in industrial units helps the molecules transportation and in other word the purification rate. Of course to this scenario addition of other phases also should be considered. Addition of a phase or an excess media to the first media produces the problem of passing molecules from the interface between phases and answer to the question of how much molecules are able to pass the interface dam. Therefore in this stage phase equilibrium coming from thermodynamics can help us to answer the question. Using different equilibrium data in handbooks helps us to construct the equilibrium curves.

On the other hand, different contact processes of crosscurrent, countercurrent and cocurrent of different phases create operating line or operating curve that can show the conditions of flows pass next to each other in mass exchanger equipment. Stagewise and differential types of contact are two usual forms of phase contact in mass exchanger equipments. The equipments used these forms of contacts are tray and packed towers and number of theoretical trays and the height of packed beds are two processing parameters that need to be calculated in separation processes.

Many good literatures have been published on separation processes. Different units have been studied in a valuable book under the title "Mass Transfer Operations" (Treybal, 1955) and added others as well, (McCabe et al., 1956), (Pavlov et al., 1979), (Henley et al., 1981), (Hines \& Maddox, 1985), (Khoury, 1995) and (Geankoplis, 2003). The analysis of different separation processes was carried out from the same point of view. The processes were 
studied in details in mentioned references and usually the classification of separation processes was carried out based on phases concerned in units, for example in transfer between gas and liquid phases, humidification, gas absorption and distillation processes were presented. But it seems classifying the units into two broad branches of 'absorptionlike' and 'desorption-like' processes can be helpful on discussion of the main aspects of mass transfer. Therefore in the present chapter, separation units taking place in towers (tray or packed-bed type) are discussed based on a common view point and set into two broad branches. The transfer of molecules presented in a phase to the other phase is investigated from dense point of view of phases. Different separation processes are divided to 'absorption-like' processes and 'desorption-like' processes and a similar analysis procedure for units contain in each category is explained. This method of analysis of separation processes maybe helpful for undergraduate students of chemical engineering and also graduate students to make a common sense between different purification techniques.

In this chapter after dividing the different units into 'absorption-like' and 'desorption-like' processes in the second section, staged processes philosophy is brought in section three and followed with a brief discussion on thermodynamics of processes in section four. Operating line or curve related to processes will be discussed in the fifth section and it follows with staircase construction in sixth section. Different equilibrium diagrams and the strategy of using difference points in process calculations will be discussed in seventh section and section eight contains the calculation of packed bed height. The chapter will be ended through a conclusion section at last.

\section{2. 'Absorption-like' and 'Desorption-like' purification processes}

There are different processes that can be applied in purification of products obtained in a chemical industry. Fig. 1 shows different separation processes that can be taking place in tray, packed-bed towers or both. Classification can be carried out based on phases presented in the processes but these processes can be classified into two big branches of 'absorptionlike' and 'desorption-like' processes as well. But before explaining these two branches it needs to describe the mass transfer basis of the purification processes.

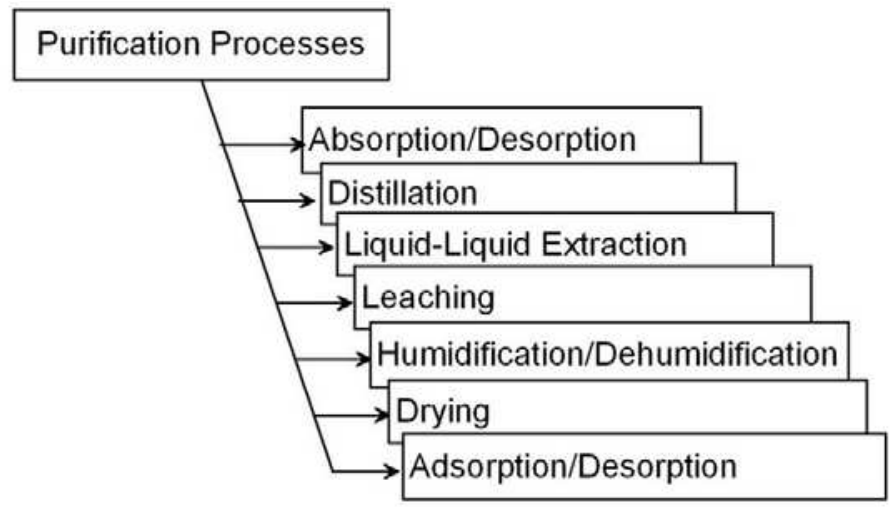

Fig. 1. Classification of purification processes that takes place in tray, packed-bed towers or both 


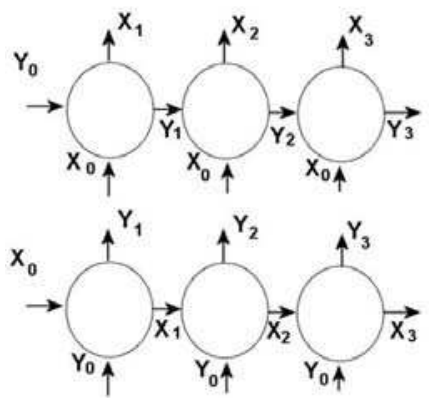

(a1)
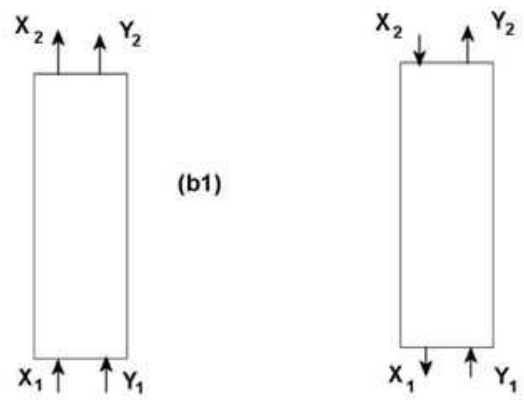

(c1)
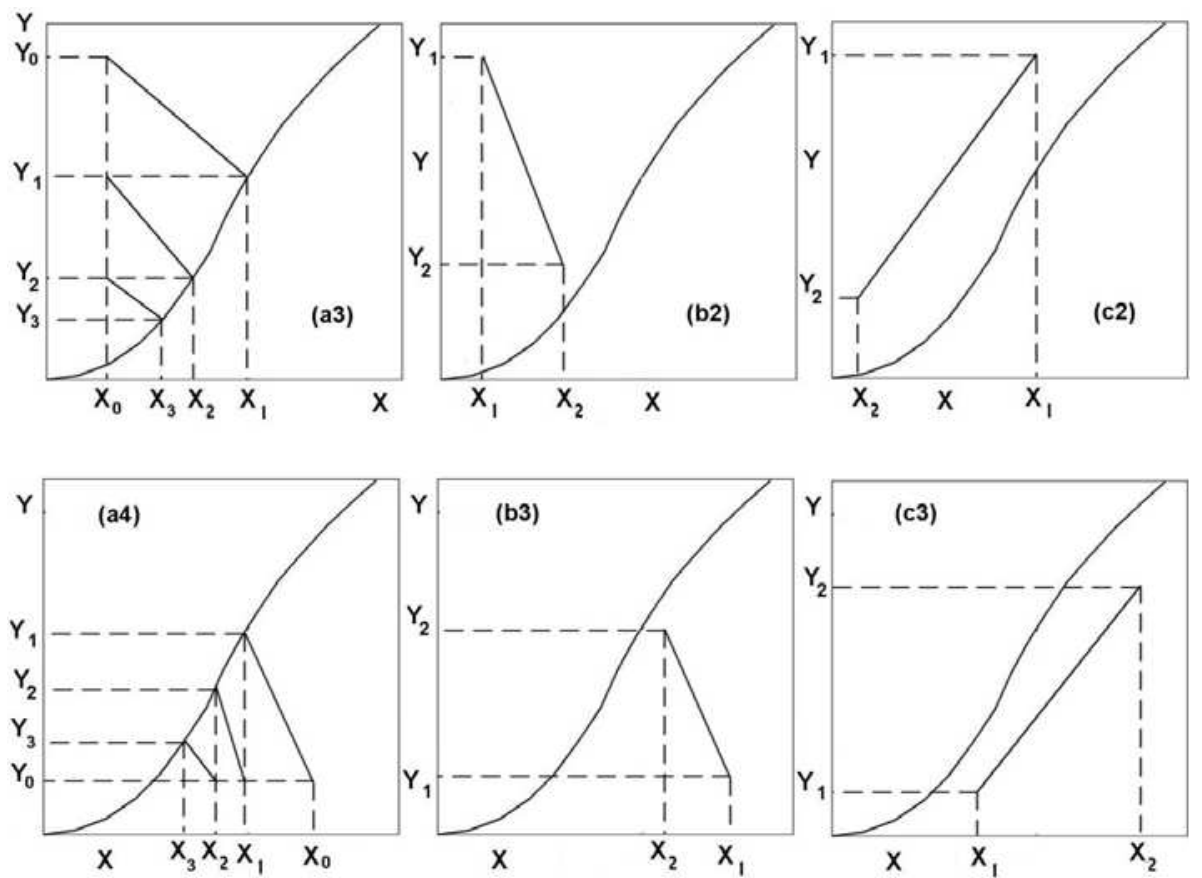

Fig. 2. Processes used in purification and variation of transferring component concentration in absorption-like and desorption-like processes; (a1, a3) crosscurrent flow, absorption-like process; (a2, a4) crosscurrent flow, desorption-like process; (b1, b2) cocurrent flow, absorptionlike process; (b1, b3) cocurrent flow, desorption-like process; (c1, c2) countercurrent flow, absorption-like process; (c1, c3) countercurrent flow, desorption-like process

Usually on diffusion and transfer of a constituent through a phase to the interface produced in contact with other phases two cases can be considered. In the first case the constituent molecules move through a less dense phase to the interface and from interface to other phase contain denser material due to the first phase. This case is called as 'absorption-like' process and can contain different processes of absorption, dehumidification and adsorption. But sometimes the molecules move from a dense phase to less dense other phase and it is called a 'desorption-like' processes. Desorption, humidification, leaching and drying processes 
can fall in this group. Distillation process that contains rectifying and stripping sections together in a tower is set in 'desorption-like' processes group. Usually Liquid-liquid extraction also falls in 'desorption-like' processes group.

Transferring mass of a component is occurred when there is a difference in component chemical potential between phases. This is a thermodynamics fact of mass transfer. The assumptions simplify this fact into measurable parameter of concentration of component in different phases. The concentration of a component i can be translated as mole or mass concentration (as mole or mass of $i$ to volume which is shown as $C_{i}$ or $\rho_{i}$, respectively), mole or mass fractions (as mole to total moles that is shown as $x_{i}$ or $y_{i}$ and as mass to total masses that is shown as $\omega_{i}$ ) and partial pressure for gaseous components (as pressure of $i$ that is shown as $\mathrm{p}_{\mathrm{i}}$ ).

From processing point of view, the differences between purification processes can be categorized in two ways of 'phases contact form' and 'component transferring form'. The contact between phases depends on direction of streams to and from the separator and can be divided into crosscurrent, cocurrent and countercurrent flows. The component transferring form also specifies the way of mass transfer and as mentioned it divides to absorption and desorption-like processes. The operation of different processes is determined from form of varying the component concentrations in streams passing the equipment due to the equilibrium condition from component transferring point of view. The variation of concentrations can be presented as an operating line and the conditions at equilibrium between phases are referred as equilibrium curve. Fig. 2 shows different contact form of phases in purification processes and the form of locating operating line and equilibrium curve in each case generally. All purification processes often fall into different cases shown in Fig. 2. The parameters $\mathrm{X}$ and $\mathrm{Y}$ show mole fraction of transferring component to mole fraction of non-transferring component and sometimes called as mole ratios. $[X=x /(1-x)$ and $\mathrm{Y}=\mathrm{y} /(1-\mathrm{y})]$

\section{Staged processes philosophy}

Transfer of a component from one phase to another phase can be occurred using the following driving forces:

a. Temperature driving force- In this case transferring heat or energy from outside the system to the desire phase causes moving the component molecules from bulk of the phase to the interface between phases and then to the other phase. Batch distillation and drying are examples of this case.

b. Concentration driving force- Increasing concentration gradient helps the component molecules to transfer more (higher mass flux) from bulk condition to the interface and through other phase. In drying process, using a gas stream with low humidity helps the drying of solid to carry out better. The reason is to impose higher humid concentration difference between bulk of the solid and the gas bulk that consequently causes the mass transfer rate to be increased.

c. Concentration and thermal driving forces simultaneously- Using energy and increasing concentration gradient simultaneously cause the transport of component molecules to be higher than cases when to impose each driving force individually. If mass and heat transfer carry out simultaneously, large number of molecules get the chance to move to the interface and be separated. In drying process using heat transfer to the solid surface and a gas medium with low humidity help the moisture inside solid to be separated more and efficiently. 
d. Hydraulic driving force- Imposing the pressure gradient using decreasing the total pressure in one phase forces the molecules that move more and faster to the interface and be separated. Drying of a moist solid in a vacuum gas media is a good example in this case that as we expect the moisture molecules are separated faster and more in comparison with the cases that vacuum condition not be used.

On the other hand, for mass transfer to carry out better some conditions can be used to increase mass flux from increasing the mass transfer coefficient viewpoint. Reaching this condition is available from using higher turbulence conditions and consequently increasing the Reynolds number. But in the present section the focus is done on increasing driving forces. The processes that are used for purification in chemical industries need at least two phases to contact each other and this contact should be performed in a contactor or mass exchanger equipment. What is important in contacting phases is that during the course of separation of components transferring molecules causes the concentration gradient to be decreased along the time and the system of finite volume from two phases gets closer to the equilibrium condition just at temperature and pressure of the system. The question is that is the equilibrium available really what we need?'. It maybe true sometimes but not often. What needs to do is contacting phases more and more or in other words stage by stage. Each stage can be considered as a control volume that mass transfer taking place on it. Imposing different operating conditions of temperature and pressure in each stage can impose different equilibrium conditions that can be accessible and the flows leaved the stage can be reached them theoretically. Therefore each stage is called as a 'theoretical stage' and the separation processes sometimes are called 'staged processes'.

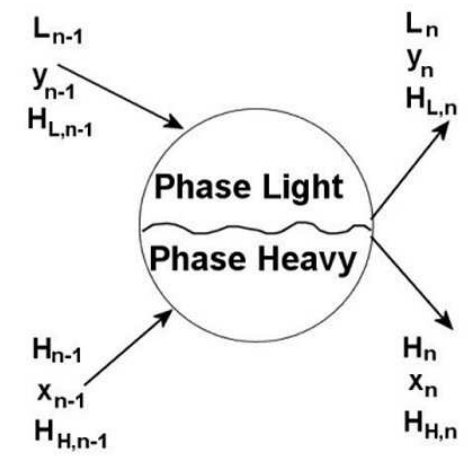

Fig. 3. Schematic of a theoretical stage $n$

Fig. 3 shows a stage as a control volume in separation processes generally. As it is shown two streams from two phases enter the stage with known flow rates, compositions and enthalpies (noted as $\mathrm{L}, \mathrm{y}$ and $\mathrm{H}_{\mathrm{L}}$ in light phase and $\mathrm{H}, \mathrm{x}, \mathrm{H}_{\mathrm{H}}$ in heavy phase, respectively) and after getting the equilibrium condition at temperature and pressure of the stage, two streams made from two phases leave the stage. To get the desire conditions for the flows leave the stage, a set of stages is often used. Therefore the streams enter the stage ' $n$ ' coming from stage ' $n-1$ ' and stage numbers are brought as subscripts of flow characteristics.

What happened on the stage, as mentioned, are the contact and consequently the component transfer between phases. Transport of mass between phases contains the phenomena of mass transfer inside a phase from bulk to the interface, passing the interface, 
and finally transfer of mass to the bulk of other phase. Fig. 4 shows two phases of $\mathrm{L}$ and $\mathrm{H}$ in contact with each other, schematically. As it is shown in Fig. 4a in contact between two phases $\mathrm{L}$ and $\mathrm{H}$, a phase interface that is a nonhomogeneous phase contains surfaces with constant properties in border zone is generated in reality. The normal vector, $\mathrm{n}$ shows the direction that properties in the phase interface are varied. Fig. $4 \mathrm{~b}$ is a theoretical equivalent figure that Gibbs suggested and used a geometrical interface (called Gibbs' interface) to replace the phase interface. Based on this model, the properties of homogeneous phases $\mathrm{L}$ and $\mathrm{H}$ are constant at top and bottom of the geometrical interface, respectively.

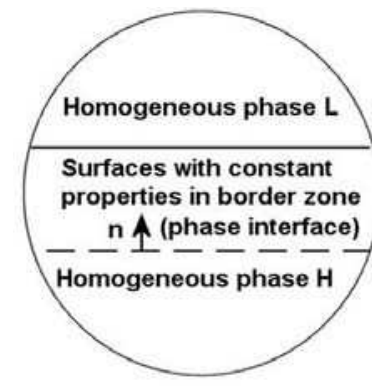

(a)

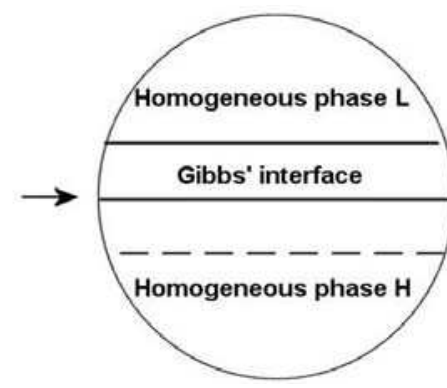

(b)

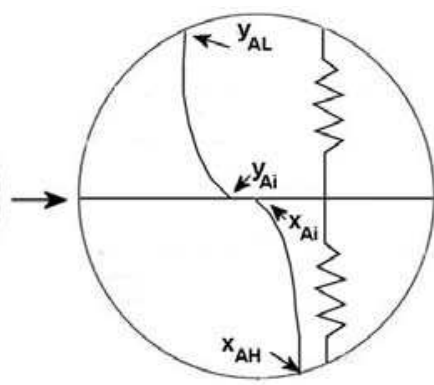

(c)

Fig. 4. Two phases $\mathrm{L}$ and $\mathrm{H}$ in contact each other; (a) In reality; (b) The model suggested by Gibbs for contacting two immiscible phases [taken from (Luikov, 1980)]; (c) The resistances against mass transfer in each phase and concentration gradients

In purification processes it needs to transfer a component or number of components from one phase to the other phase. By considering the model proposed by Gibbs, transfer of a component should be carried out from bulk of a phase to geometrical interface, equilibrium should be existed between phases on interface, and then transfer of component is occurred from interface to the bulk of other phase. The resistances against mass transfer from bulk to bulk are shown in Fig.4c. The component A mole fraction decreases from yAL at bulk to yAi at geometrical interface in phase $\mathrm{L}$ side. The A mole fraction at interface in phase $\mathrm{H}$ side, $\mathrm{x}_{\mathrm{Ai}}$ is in equilibrium with $\mathrm{y}_{\mathrm{Ai}}$ and can be calculated from equilibrium data. Finally a concentration gradient through phase $\mathrm{H}$ is seen as shown in Fig. 4c. As it is obtained logically, equality of component A chemical potentials in two phases $\mathrm{L}$ and $\mathrm{H}\left(\mu_{\mathrm{AL}}\right.$ and $\left.\mu_{\mathrm{AH}}\right)$ is not meaning the equality of mole fractions in equilibrium condition at interface.

Knowing about resistances against mass transfer in contacting phases helps the engineer as a separation equipment designer to decide carefully on design of stages in terms of residence time of phases on stage and level of turbulency needs on phases to get the equilibrium condition for the streams leaved the stage. The phase with higher resistance shows the controlling step in mass transfer and needs to have more turbulency in mass exchanger.

Analysis on resistances can be carried out from writing the flux of mass transfer in respect of cases that can be considered as 'equimolar counterdiffusion' or mass transfer through 'stagnant nondiffusing components'. Indeed the classification can be performed as conditions of high or low mass transfer flux. In low mass transfer flux and in the case of 'equimolar counterdiffusion', the flux of component A can be formulated similar to convective heat transfer flux as 


$$
\mathrm{N}_{\mathrm{A}}=\mathrm{k}_{\mathrm{y}}^{\prime}\left(\mathrm{y}_{\mathrm{AL}}-\mathrm{y}_{\mathrm{Ai}}\right)=\mathrm{k}_{\mathrm{x}}^{\prime}\left(\mathrm{x}_{\mathrm{Ai}}-\mathrm{x}_{\mathrm{AH}}\right)
$$

where $\mathrm{N}_{\mathrm{A}}$ is the convective mass transfer flux, $\mathrm{k}_{\mathrm{y}}^{\prime}$ and $\mathrm{k}_{\mathrm{x}}^{\prime}$ are the convective mass transfer coefficients in light and heavy phases, respectively, $\mathrm{y}_{\mathrm{AL}}$ and $\mathrm{y}_{\mathrm{Ai}}$ are the mole fractions of component $\mathrm{A}$ in the bulk and interface side of light phase, and $\mathrm{x}_{\mathrm{Ai}}$ and $\mathrm{x}_{\mathrm{AH}}$ are the component A mole fraction at interface side and bulk of heavy phase, respectively. Equation (1) can be figured as an analog electrical relation of voltage $=$ (resistance)(current). The mole fraction differences play as voltage or driving force, flux as the current, and finally inverse of convective mass transfer coefficients as resistances. From equation (1) the operating line for a theoretical stage can be derived as

$$
-\frac{\mathrm{k}_{\mathrm{x}}^{\prime}}{\mathrm{k}_{\mathrm{y}}^{\prime}}=\frac{\mathrm{y}_{\mathrm{AL}}-\mathrm{y}_{\mathrm{Ai}}}{\mathrm{x}_{\mathrm{AH}}-\mathrm{x}_{\mathrm{Ai}}}
$$

The above operating line is passed from two points of $\left(\mathrm{x}_{\mathrm{AH}}, \mathrm{y}_{\mathrm{AL}}\right)$ and $\left(\mathrm{x}_{\mathrm{Ai}}, \mathrm{y}_{\mathrm{Ai}}\right)$ with a negative slope of $-k_{x}^{\prime} / k_{y}^{\prime}$. The operating line, $M N$ is shown in Fig. 5 . As it is seen the point $N$ shows mole fractions on interface and is located on the equilibrium curve.

Equation (1) can also be written based on overall mass transfer coefficients of $\mathrm{K}_{\mathrm{y}}^{\prime}$ and $\mathrm{K}^{\prime}{ }_{\mathrm{x}}$, but only one problem remains that 'what type of mole fractions should be used compatible with $\mathrm{x}_{\mathrm{AH}}$ and $\mathrm{y}_{\mathrm{AL}}$ ?'. Therefore when the driving force is written based on the mole fraction difference in phase-L, yAL is considered for the concentration at starting point of mass transfer and we should consider a mole fraction at the end of way of mass transfer in bulk of the phase- $\mathrm{H}$ and equivalent with $\mathrm{x}_{\mathrm{AH}}$. This value can be called $\mathrm{yA}_{\mathrm{A}}{ }^{*}$, a mole fraction in phase$\mathrm{L}$ in equilibrium with $\mathrm{x}_{\mathrm{AH}}$ on equilibrium curve, as shown in Fig. 5 . This procedure can be taken for overall driving force based on phase- $\mathrm{H}$ as well. Consequently, the flux relation based on the overall driving force is written as follows

$$
\mathrm{N}_{\mathrm{A}}=\mathrm{K}_{\mathrm{y}}^{\prime}\left(\mathrm{y}_{\mathrm{AL}}-\mathrm{y}_{\mathrm{A}}^{*}\right)=\mathrm{K}_{\mathrm{x}}^{\prime}\left(\mathrm{x}_{\mathrm{A}}^{*}-\mathrm{x}_{\mathrm{AH}}\right)
$$

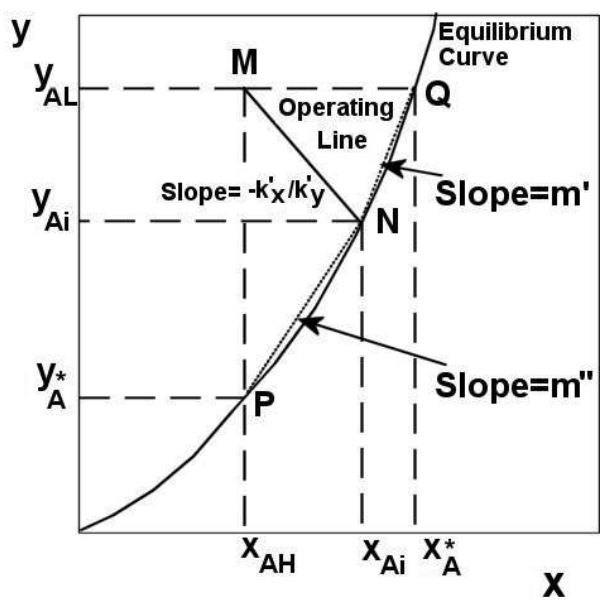

Fig. 5. The operating line of a theoretical stage, line MN 
The overall driving force, mole fraction difference, based on light phase can be written mathematically as

$$
\mathrm{y}_{\mathrm{AL}}-\mathrm{y}_{\mathrm{A}}^{*}=\left(\mathrm{y}_{\mathrm{AL}}-\mathrm{y}_{\mathrm{Ai}}\right)+\left(\mathrm{y}_{\mathrm{Ai}}-\mathrm{y}_{\mathrm{A}}^{*}\right)
$$

By setting equivalent relations for driving forces using equations (1), (3) and Fig. 5 and after simplifying we have

$$
\frac{1}{\mathrm{~K}_{\mathrm{y}}^{\prime}}=\frac{1}{\mathrm{k}_{\mathrm{y}}^{\prime}}+\frac{\mathrm{m}^{\prime \prime}}{\mathrm{k}_{\mathrm{x}}^{\prime}}
$$

This relation shows that the overall resistance against mass transfer is equal the resistance in light phase plus $\mathrm{m}^{\prime \prime}$ times the resistance in heavy phase.

Analogous following relation can be derived if the overall driving force is written based on the heavy phase

$$
\frac{1}{\mathrm{~K}_{\mathrm{x}}^{\prime}}=\frac{1}{\mathrm{k}_{\mathrm{x}}^{\prime}}+\frac{1}{\mathrm{~m}^{\prime} \mathrm{k}_{\mathrm{y}}^{\prime}}
$$

Equations (5) and (6) have been derived in the case of equimolar counterdiffusion that for diffusion of component A through stagnant component, other relations can be derived (Geankoplis, 2003).

\section{Thermodynamics}

The aim of studying thermodynamics of different processes is obtaining the equilibrium condition that we assume in theoretical ideal conditions that can be accessible in the interface between phases. Therefore this condition is ideal and is not available in real operation of units. Usually the concentration of separated constituent in a less dense phase can be drawn versus its concentration in the second phase and called as the equilibrium curve. For using better from equilibrium curves in separation processes, dimensionless concentrations as weight or mole fractions are used. Sometimes when gaseous phase considered as a light phase, the partial pressure can be used as concentration.

Thermodynamics probably is the principal part of analysis of separation processes. This part directly is connected to physical and chemical properties of materials and needs to be investigated experimentally before using any mathematical models to predict the equilibrium data. We are facing with a broad subject in thermodynamics called 'phase equilibria' and as it is noted intellectually in the valuable book of 'The properties of gases and liquids' (Poling, Prausnitz, \& O'Connell, 2001), working on this part of science needs more attention as experimentally investigation, careful using reliable data published in literatures and using mathematical models that give reliable results. For this reason in this section a brief discussion on phase equilibria is presented. Vapor-liquid, liquid-liquid, solidliquid, gas-liquid and gas-solid equilibria are discussed in this section.

\subsection{Vapor-liquid equilibria (VLE)}

At the equilibrium between vapor and liquid phases, for a mixture with m-components, the following relation is written between fugacity of each component $i, f_{i}$, as 


$$
\mathrm{f}_{\mathrm{i}}^{\mathrm{v}}=\mathrm{f}_{\mathrm{i}}^{\mathrm{l}},(\mathrm{i}=1,2, \ldots, \mathrm{m})
$$

where superscripts $\mathrm{v}$ and 1 show vapor and liquid phases, respectively. Simplifying the above equation using equivalent relations for right and left hand sides gives

$$
\mathrm{y}_{\mathrm{i}} \Phi_{\mathrm{i}} \mathrm{P}=\mathrm{x}_{\mathrm{i}} \gamma_{\mathrm{i}} \mathrm{f}_{\mathrm{i}}^{0}
$$

where $y_{i}$ and $x_{i}$ are mole fractions of component $i$ in the vapor and liquid phases, respectively, $\Phi_{i}$ and $\gamma_{i}$ are the fugacity and activity coefficients of component $i$ in the vapor and liquid phases, respectively, $\mathrm{P}$ is the total pressure in vapor phase and $\mathrm{f}_{\mathrm{i}}{ }^{0}$ is the standardstate fugacity. Replacing an equivalent value for standard-state fugacity, the following relation is obtained

$$
\mathrm{y}_{\mathrm{i}} \Phi_{\mathrm{i}} \mathrm{P}=\mathrm{x}_{\mathrm{i}} \gamma_{\mathrm{i}} \mathrm{P}_{\mathrm{i}}^{\mathrm{sat}} \exp \left[\int_{0}^{\mathrm{P}_{\mathrm{i}}^{\mathrm{sat}}}\left(\mathrm{Z}_{\mathrm{i}}-1\right) \frac{\mathrm{dP}}{\mathrm{P}}+\frac{1}{\mathrm{RT}} \int_{\mathrm{P}_{\mathrm{i}}^{\text {sat }}}^{\mathrm{P}} \mathrm{V}_{\mathrm{i}} \mathrm{dP}\right]
$$

where $P_{i}$ sat is the vapor pressure of pure $i, Z_{i}$ is the vapor-phase compressibility factor, $V_{i}$ is the liquid-phase molar volume, $R$ is the universal gas constant and $T$ is the absolute temperature.

The simplest form of governing equation on VLE is the Raoult's law which is suitable to low pressure and considers ideality for both liquid $\left(\gamma_{\mathrm{i}}=1\right)$ and vapor $\left(Z_{\mathrm{i}}=1, \Phi_{\mathrm{i}}=1\right)$ phases. Indeed it assumes that the liquid molar volume is negligible or $\mathrm{P} \cong \mathrm{P}_{\mathrm{i}}$ sat. The Raoult's law is written as

$$
\mathrm{y}_{\mathrm{i}} \mathrm{P}=\mathrm{x}_{\mathrm{i}} \mathrm{P}_{\mathrm{i}}^{\mathrm{sat}}
$$

The LHS of this equation shows partial pressure of component $i$ in the vapor phase, $P_{i}$. For a binary system, this relation can be written for two components of 1 and 2 as

$$
\begin{aligned}
& \mathrm{P}_{1}=\mathrm{x}_{1} \mathrm{P}_{1}^{\text {sat }} \\
& \mathrm{P}_{2}=\mathrm{x}_{2} \mathrm{P}_{2}^{\text {sat }}
\end{aligned}
$$

It depicts that at the constant temperature, the partial pressure of each components has a linear function of mole fraction in liquid phase. Summation of partial pressures on both components makes the total pressure versus $x_{1}$ curve (the bubble-point curve). In Raoult's law partial pressure curves for two components and the bubble-point curve are linear, but some real mixtures show deviations from Raoult's law. If these curves do not show the linear behavior and lie above the Raoult's law lines, the system shows positive deviations from Raoult's law and there are negative deviations when curves lie below the Raoult's law lines. These behaviors come from both liquid and vapor phase non-idealities. Based on equation (9), in liquid phase the non ideality comes from $\gamma_{i}$ and integral of $V_{i}$ and in the vapor phase two terms of $\Phi_{i}$ and integral containing $Z_{i}$ cause the deviations.

But at low pressures, ideality assumption for the real liquid mixtures sometimes is not true and in this case

$$
\mathrm{y}_{\mathrm{i}} \mathrm{P}=\mathrm{x}_{\mathrm{i}} \gamma_{\mathrm{i}} \mathrm{P}_{\mathrm{i}}^{\mathrm{sat}}
$$




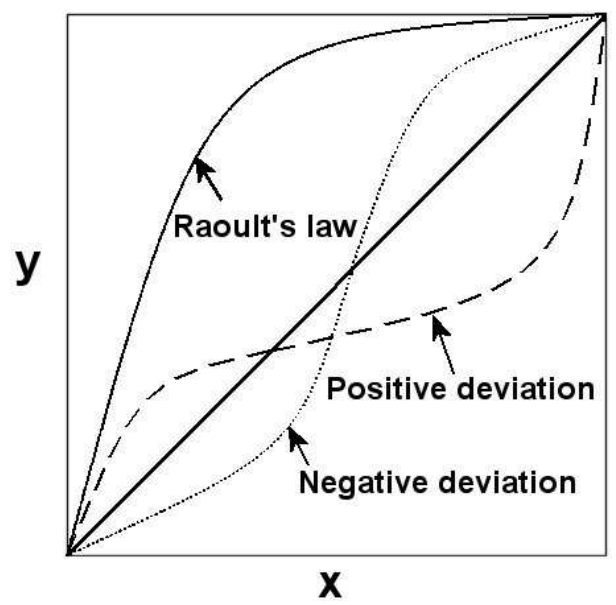

Fig. 6. Equilibrium curves obtained from Raoult's law and non-ideal situations of positive and negative deviations from Raoult's law

If $\gamma_{i}>1$, the system shows positive deviations and vice versa the negative deviations are seen for the case when $\gamma_{i<1}$. It should be noted that occurrence of azeotropes $\left(y_{i}=x_{i}\right)$ sometimes causes the deviations to occur. A significant difference in vapor pressures or bubble points of pure components or very close vapor pressures of pure constituents of mixture can generate azeotropes. Fig. 6 shows the equilibrium curves in ideal (using Raoult's law) and non-ideal (positive and negative deviations) situations. As it is seen the azeotropes occurred in non-ideal situations.

\subsection{Liquid-liquid equilibria (LLE)}

Liquid-liquid equilibria can be described from the term of miscibility on two liquid phases. When two liquid phases are mixed, it can produce one phase from miscible liquid phases or two immiscible phases in equilibrium with each other. Two liquid phases often have partial miscibility in each other. It means that under some operating conditions of pressure, temperature and composition, they are miscible and produce one final phase or immiscible and show a two-phase region. Temperature, pressure and composition are variables that can affect the miscibility of liquid phases. Through these, the pressure is less important on liquid phases, and mostly the Tx diagram is considered to show the behavior of mixed liquids.

The region of homogeneous liquid solution and two-phase zone schematically are shown in Fig. 7. As it is shown, in the region outside the dome-shaped curve, two liquid phases are miscible and one homogeneous phase is made but inside the curve a two-phase region is produced. A mixture of two liquids that lies inside the dome, is not produced a stable single phase and splits into two liquid phases in equilibrium with each other that each one has its own composition.

For binary systems, outside the dome-shaped curve, one homogeneous phase is existed and based on the phase rule; there are 3 degrees of freedom (2-ח+m for an m-components system with $\Pi$ phases). It means that for each point outside the dome zone; pressure, temperature and composition of the mixed liquids should be fixed to obtain all properties of one produced phase. On the other hand, inside the dome zone; the degree of freedom is 
calculated as 2 and by fixing pressure and composition or pressure and temperature, the other properties of resultant phases are fixed. With this discussion, each point like E, inside the dome zone splits into two phases with compositions at B and A that obtained from drawing a horizontal line passing through the point, called tie line, as depicted in Fig. 7. As it is seen, two phases produced at B and A are rich phases that each one is enriched of one constituent. The lever rule is applied to calculate the ratio of total moles in two phases as well.

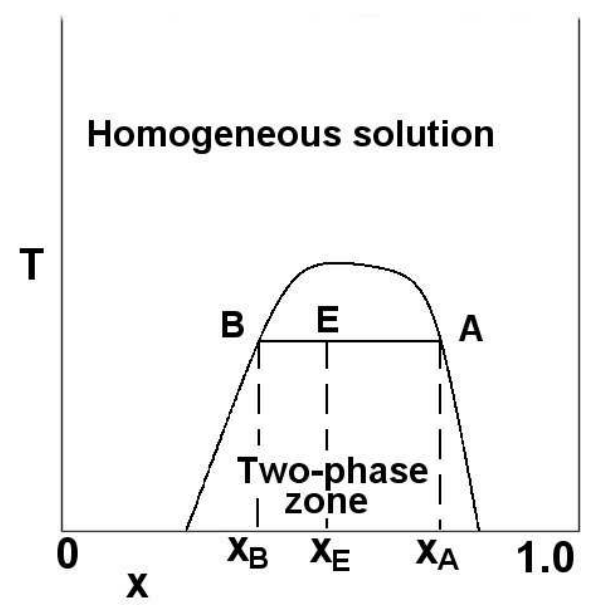

Fig. 7. Schematic of a Tx diagram for liquid-liquid equilibria

But application of liquid-liquid equilibria in separation processes needs the condition when at least a system of three components presents. Two liquid phases have partial miscibility in each other and the third constituent is miscible in two mentioned liquids completely. This is a usual case in separation processes. Therefore in this case an equilateral triangular diagram is used to show where we are in separation process. A triangular diagram schematically is shown in Fig. 8a. Each of three apexes is shown a pure component and a point inside triangle shows a ternary mixture. If the point lies inside the dome zone it is not a stable mixture and splits into two phases that each one is enriched from one constituent. Outside the dome zone, there is only one homogeneous phase and on the sides $\mathrm{AC}$ and $\mathrm{BC}$ of the triangle, binary systems are presented. The compositions of each point inside the triangle are obtained from drawing perpendiculars to each side. Length of perpendicular to each side of the triangle shows the value of composition opposite to the side and ratio of length of each perpendicular to summation of them shows the mass or mole fraction of components. The tie line passes through a point $\mathrm{M}$ inside the dome zone can show the compositions of phases produced at $\mathrm{D}$ and $\mathrm{E}$ as presented in Fig. 8a.

For simplicity, the equilibrium data can be plotted on a rectangular coordinates graph as well. As it is shown in Fig. $8 \mathrm{~b}$ each rectangular coordinate shows the mass or mole fraction of one component. In this figure the liquid phase at point $\mathrm{E}$ is rich from transferring component $C$ and its mass fraction is shown as $y_{E}$, the mass fraction of $C$ in liquid phase at point $D$ is shown as $x_{D}$ and finally the mass fraction of component $C$ in unstable liquid mixture at point $\mathrm{M}$ is depicted as $\mathrm{z}_{\mathrm{M}}$. 


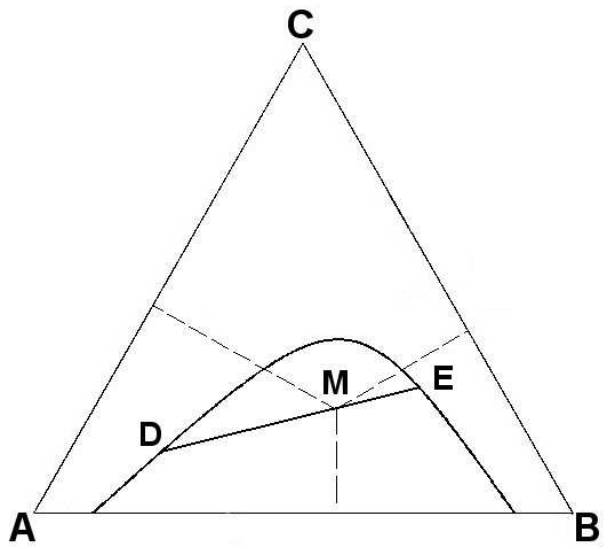

(a)

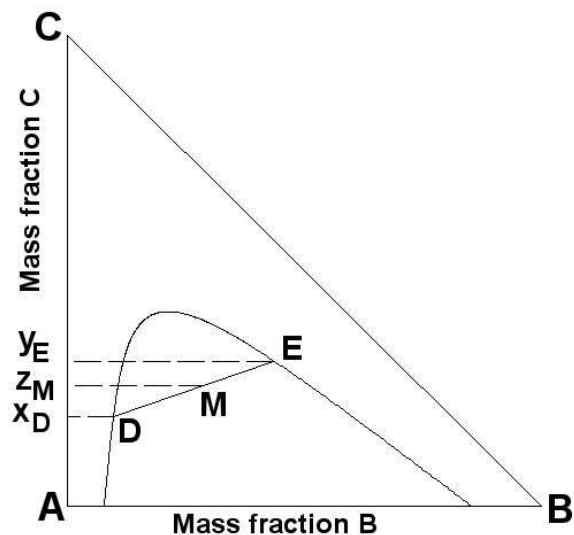

(b)

Fig. 8. Liquid-liquid equilibrium; (a) Equilateral triangular coordinates; (b) Rectangular coordinates

\subsection{Solid-liquid equilibria (SLE)}

The solubility of a solid into a liquid is a parameter that depends upon equilibria existed between solid and liquid phases. A solid phase can be dissolved into a specified liquid phase completely or it can be partially dissolved under some conditions of pressure and temperature.

The solubility of a solid in a liquid depends upon intermolecular forces between solid and liquid, the melting point and enthalpy or entropy of fusion of the solid. Between two different solids demonstrating the same intermolecular forces with a liquid, the solid with higher melting point and higher enthalpy of fusion has lower solubility. But when a solute trapped inside a solid matrix (marc) immiscible in the liquid solvent, it is assumed that the equilibrium mole fraction of solute in solvent or the solubility is complete and a ternary system like what investigated in the liquid-liquid equilibria should be analyzed.

Therefore the SLE ternary systems are considered to include one solid phase immiscible in liquid solvent phase and a solute trapped in the solid matrix. The equilateral triangular diagrams are used to show the equilibrium between different components. Usually the solute can be dissolved into solvent completely and there is a limit for solid matrix to keep solute inside its porous structure. Fig. 9 shows a typical equilateral triangular diagram in which different components are set on each apex and show the marc (A), pure solvent (C) and pure solute (B). The curve abcde in the diagram shows the limit between two and three phases. The left side demonstrates the three phase region that three components are distinguishable. In this region a mixture of three phases contains more solid matrix than other two components. Also the region in the right side of the curve belongs to the mixtures with two phases. One phase is rich from the solid matrix (points b, c and d) and another is rich from liquid solvent (points $b^{\prime}, c^{\prime}$ and $d^{\prime}$ ). All the solute is distributed between these two phases. Indeed as it is seen for the phase rich from the solid matrix that located on the curve, there are significant amounts of solvent and solute trapped in the porous structure of the solid. 
If the solid matrix does not adsorb the solute molecules, the concentration of solute inside pores is the same as that inside the phase rich from the solvent in equilibrium with.

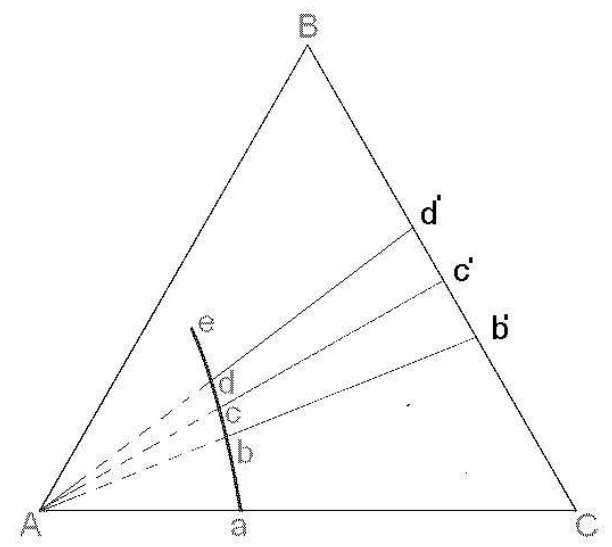

Fig. 9. Equilibrium in solid-liquid system

\subsection{Gas-liquid equilibria}

Equilibrium between a gas and a liquid can be studied from two different viewpoints. In first case, a constituent of gas phase can be transferred to the liquid phase and in other word it can dissolve into the liquid. In this case the limitation for the gas solubility in liquid is the matter of fact and needs to be studied. But the second case is regarded as transfer of liquid constituent into the gas phase and the transport of molecules is continued to make a saturated gas from the liquid constituent molecules.

Each case is really depending upon operating conditions of temperature and pressure and also concentrations of other components presented in the system. Thermodynamic relationships can describe the relation between different parameters affecting equilibrium state but the reliable results in each case need to be obtained experimentally.

The solubility of a gas constituent through a liquid phase is depending to the temperature and increasing the temperature decreases the solubility. Also increasing pressure in gas phase helps the gaseous molecules to dissolve better in the liquid. When gaseous molecules dissolve in liquid phase a broad range of mixtures can be studied from a pure initial liquid to a pure liquid produced from gaseous constituent molecules. Obtaining the solubility of a component in liquid depends on interaction between solute and solvent molecules as well and this subject has been investigated in thermodynamics of ideal and non-ideal solutions. Based on what obtained in this scope, the molecules of similar group of materials e.g. alcohols, alkanes, alkenes etc interact each other normally like molecules of pure materials individually and in other word can produce an ideal solution. But when the molecules constituting solute and solvent be different from each other and belong to different groups, they can interact each other differently and produce non-ideal solutions. The Raoult's law predicts the behavior of ideal solutions very well but when solutions show a non-ideal behavior it fails. In non-ideal solutions the partial pressure of gaseous component in gas phase is not proportional with component mole fraction in the liquid phase with proportionality coefficient of component vapor pressure but in this case if solute molecules dissolve limited into the liquid phase, the Henry's law is governed and is written as 


$$
\overline{\mathrm{P}}_{\mathrm{i}}^{*}=\mathrm{H}_{\mathrm{i}} \mathrm{x}_{\mathrm{i}}
$$

where $\overline{\mathrm{P}}_{i}^{*}$ is the partial pressure of component $\mathrm{i}\left(=\mathrm{Py}_{\mathrm{i}}\right)$ and $\mathrm{H}_{\mathrm{i}}$ is the Henry's constant for component i. Fig. 10 shows the curve $f_{i}^{v}$ versus $x_{i}$ in general form as $\bar{P}_{i}^{*}$ is replaced with $f_{i}^{v}$ based on the Henry's law.

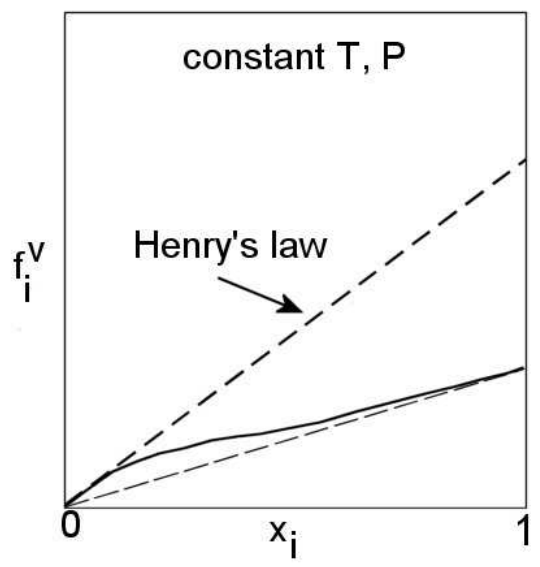

Fig. 10. Henry's law for dilute solution behaviors

\subsection{Gas-solid equilibria}

When two phases of solid and gas contacted each other, the final amount of gas molecules inside the gas phase and those attached to the solid surfaces depends on equilibria between phases. The equilibrium in this case means that reaching a partial saturation of unsaturated forces at the surface of solid phase from the way of interaction with the gas molecules in gas phase (Rudzinski, Steele, \& Zgrablich, 1997). Different interactions between gas molecules in the gas phase and solid surface molecules can be occurred and gas molecules can interact with each other when adsorbed on the solid surface as well.

To obtain a proper equilibrium relation between fraction of coverage of a solid $(\theta)$ and the pressure of a gaseous adsorbate (p), it needs to know microscopic phenomenon of covering the solid surface by gas molecules and all phenomena happened in gas molecules adsorption. Different forces occurred between molecules, effect of operating conditions on molecular interactions and many other subjects should be studied. The gas molecules can be adsorbed physically (physisorption) or chemically (chemisorption) to the solid surface. The forces between molecules in physisorption are of Van der Waals type when in chemisorption, chemical bonds which are much strong ( $>0.5 \mathrm{eV}$ energy per each molecule adsorbed) are occurred between molecules. Search to find a good equilibrium model $[\theta=\theta(p)]$ that called an 'adsorption isotherm' needs to consider different assumptions on coverage of solid surface by monolayer/multilayer of gas molecules, homogeneity of solid surface, interaction of gas molecules located on the solid surface and etc. Assumption of monolayer or multilayer coverage of solid surface by gas molecules depends upon the type of forces between gas and solid molecules. In physisorption processes, multilayer of gas molecules can be produced on the solid surface though monolayer of gas molecules is made in the case of chemisorption. Homogeneity of solid surface results producing the uniform 
sites for gas molecules to be adsorbed energetically. Other subject needs to be studied is the answer to this question that how strong be the forces between solid and gas molecules in adsorbing sites. In other word do the gas molecules can slide on solid surface and are mobile or they fixed on sites and localized.

For gas molecules or adsorbate to be localized on the solid surface, the energy between solid molecules on the surface and adsorbate should be higher than thermal energy of kT (where $\mathrm{k}$ is the Boltzmann constant and $\mathrm{T}$ is the absolute temperature). High value of $\mathrm{T}$ means that the energy for surface diffusion is in a range that causes the adsorbed molecules to move on the solid surface and be mobilized. In this case (monolayer localized adsorption), the Langmuir model and Fowler-Guggenheim model are used. Different models were also presented for monolayer mobile adsorption. The Volmer and Hill-de Boer isotherms are considered in this case. The BET (Brunauer, Emmet,Teller) and FHH (Frenkel, Halsey, Hill) isotherms were also presented in the case of multilayer localized adsorption. In isotherms mentioned, the solid surface is assumed to be ideal and homogeneous but in reality this assumption cannot be true most of the times. The structure of solid surface and presence of different compounds and phases are characteristics of non-homogeneity of solid surface. In real cases three isotherms of Freundlich, Dubinin-Radushkevich and Temkin were used more in monolayer adsorption. A good collection of different researches on solid-gas equilibria was presented in ref. (Rudzinski, Steele, \& Zgrablich, 1997).

Based on what happened in reality on the solid surface and the gas adsorbed, different mathematical models were presented. Through models proposed, some were used widely. Langmuir isotherm model applying to monolayer localized adsorption is obtained from equating rates of adsorption and desorption of the gas molecules on the solid surface and finally the following equation is obtained

$$
\mathrm{V}=\frac{\mathrm{V}_{\mathrm{m}} \mathrm{bp}}{1+\mathrm{bp}}
$$

where $\mathrm{V}$ is the total volume adsorbed, $\mathrm{V}_{\mathrm{m}}$ is the volume of the gas required to form a completed unimolecular layer on the adsorbent surface $\left(\theta=\mathrm{V} / \mathrm{V}_{\mathrm{m}}\right.$ is the fraction of solid surface covered by the gas molecules), $\mathrm{b}$ is defined as the adsorption equilibrium constant (ratio of adsorption to desorption rate constants) and $\mathrm{p}$ is the gas pressure. The adsorption equilibrium constant, $b$, is a function of temperature and materials that play as solid adsorbent and the gaseous adsorbate. The Langmuir model can be written as another form as

$$
\mathrm{q}=\frac{\mathrm{QK}_{\mathrm{L}} \mathrm{C}}{1+\mathrm{K}_{\mathrm{L}} \mathrm{C}}
$$

where $\mathrm{q}$ is the equilibrium concentration of adsorbate in solid phase as mass adsorbate per mass adsorbent, $\mathrm{Q}$ is the maximum adsorbate concentration in solid phase as mass adsorbate per mass adsorbent, $\mathrm{K}_{\mathrm{L}}$ is the equilibrium constant and $\mathrm{C}$ is the adsorbate concentration in the fluid phase as moles per volume. The Langmuir isotherm is shown in Fig. 11a.

Brunauer, Emmet and Teller (BET) developed the method used to get the Langmuir isotherm for multilayer adsorption on the solid surface. In this model only the first layer of adsorbate is localized on solid sites based on adsorption forces between adsorbent-adsorbate molecules. The second, third and other layers interact as condensation-like process. The BET isotherm can generate $\mathrm{S}$-shaped equilibrium curve and is written as 


$$
\mathrm{V}=\frac{\mathrm{V}_{\mathrm{m}} \mathrm{cp}}{\left(\mathrm{p}_{\mathrm{o}}-\mathrm{p}\right)\left[1+(\mathrm{c}-1) \mathrm{p} / \mathrm{p}_{\mathrm{o}}\right]}
$$

where $\mathrm{p}_{\mathrm{o}}$ is the vapor pressure of adsorbate liquid and $\mathrm{c}$ is a constant that can be defined as

$$
\mathrm{c}=\mathrm{e}^{\left(\mathrm{E}_{1}-\mathrm{E}_{\mathrm{L}}\right) / \mathrm{RT}}
$$

where $E_{1}$ and $E_{L}$ are heat of adsorption in the first layer and heat of condensation in other layers, respectively, and $\mathrm{T}$ is the absolute temperature. Other form of BET model is written as

$$
q=\frac{\mathrm{QK}_{\mathrm{L}} \mathrm{p}}{\left[1-\left(\mathrm{p} / \mathrm{p}_{\mathrm{o}}\right)\right]\left[1+\mathrm{K}_{\mathrm{L}} \mathrm{p}+\left(\mathrm{p} / \mathrm{p}_{\mathrm{o}}\right)\right]}
$$

The BET isotherm based on the above equation is brought as Fig. 11b. Derivation of two models proposed above was based on kinetic arguments but a semiempirical isotherm model that is used frequently belongs to Freundlich. This equation is written in power form mathematically as

$$
\mathrm{V}=\mathrm{V}_{\mathrm{m}} \mathrm{bp} \mathrm{p}^{1 / \mathrm{n}}
$$

where $\mathrm{n}$ is a constant. The other form for Freundlich model can be written as

$$
\mathrm{q}=\mathrm{K}_{\mathrm{F}} \mathrm{p}^{1 / \mathrm{n}}
$$

where $\mathrm{K}_{\mathrm{F}}$ is a constant. The Freundlich model of adsorption can be drawn as two types shown in Fig. 11(a and c) for values $n>1$ and $n<1$, respectively. For $n=1$ this relation can show a linear type of adsorption isotherm as well but the favorable isotherms are considered as shown in Fig. 11a.

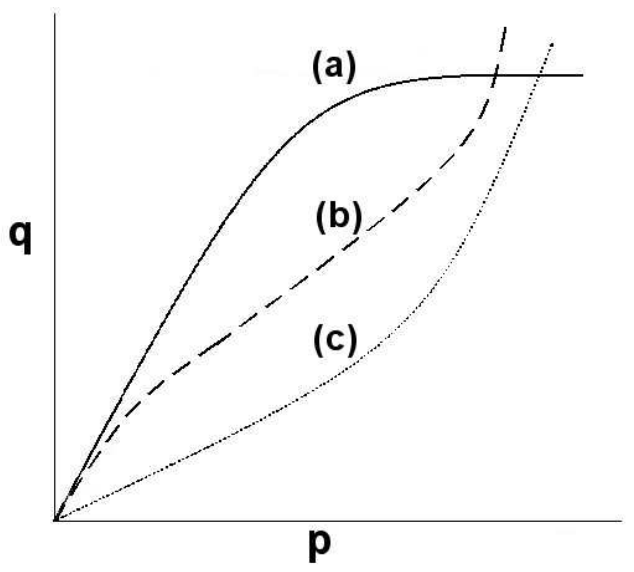

Fig. 11. Different isotherms; (a) The Langmuir and Freundlich ( $n>1)$ isotherms; (b) The BET isotherm; (c) The Freundlich isotherm $(n<1)$ 


\section{Operating behavior of flows inside a separator}

After obtaining equilibrium data carefully, the first step of separation process analysis means analysis of operating behavior of flows inside separating vessel (tray or packed-bed towers) that should be studied. Behavior of flows passes inside separators is dependent directly on the flow form and contact type of phases. In this section operating lines or curves are obtained from mass balance equations in different contact forms of crosscurrent, cocurrent and countercurrent flows inside multistage and differential separators.

Before investigating the different contact types, it needs to define different notations used for flow streams. We consider that in separation processes that often two phases contact each other; one phase can be assumed as light phase in comparison with other phase that can be called heavy phase, i.e. in adsorption process gas or liquid phase plays the role as light phase and solid phase as a heavy phase. Therefore letters $\mathrm{L}$ and $\mathrm{H}$ are used for light and heavy phases, respectively. For simplicity on writing formulations, the stagnant part of streams are defined as $\mathrm{L}_{\mathrm{s}}$ through light and $\mathrm{H}_{\mathrm{s}}$ through heavy phases (their units are as, $\mathrm{kg}$ or kmole of stagnant component/time). The mole or mass fraction of separating component in light and heavy phases defined as $y$ and $x$, respectively. Number of each stage is brought as indices for flows leaving the stage. Definition of two parameters also is useful in formulating mass balance equations and finally the operating behavior of the process. $X$ and $\mathrm{Y}$ are defined as mole/ mass fraction of transferring component to mole/mass fraction of stagnant components. As mentioned before the relation between $\mathrm{y}$ and $\mathrm{Y}$ is as follows

$$
\mathrm{Y}=\frac{\mathrm{y}}{1-\mathrm{y}}
$$

A similar relation is defined for relation between $\mathrm{x}$ and $\mathrm{X}$.

\subsection{Crosscurrent form of contact}

This form of contact is used on different processes of leaching, adsorption and liquid-liquid extraction. In crosscurrent operation one phase contacts with the streams of other phase in constant properties. This kind of contact causes keeping high driving force in each stage and consequently high mass transfer rate. Fig. 12 shows an absorption-like process that operates in a crosscurrent form of operation, schematically. The mass balance equation for stage $n$ is written as

$$
\mathrm{H}_{\mathrm{s}} \mathrm{X}_{0}+\mathrm{L}_{\mathrm{s}} \mathrm{Y}_{\mathrm{n}-1}=\mathrm{H}_{\mathrm{s}} \mathrm{X}_{\mathrm{n}}+\mathrm{L}_{\mathrm{s}} \mathrm{Y}_{\mathrm{n}}
$$

After simplifying, the operating line is obtained as follows

$$
-\frac{\mathrm{H}_{\mathrm{s}}}{\mathrm{L}_{\mathrm{s}}}=\frac{\mathrm{Y}_{\mathrm{n}}-\mathrm{Y}_{\mathrm{n}-1}}{\mathrm{X}_{\mathrm{n}}-\mathrm{X}_{0}}
$$

Lines with negative slopes of $-\mathrm{H}_{\mathrm{s}} / \mathrm{L}_{\mathrm{s}}$ are operating lines in this form of contact. In Fig. 12 the flow rates of heavy phase are assumed to be the same to the all stages but they may be different and consequently parallel operating lines are not obtained necessarily.

As it is seen the mole fraction of transferring component in light phase is decreased in each stage and using higher flow rate for heavy phase causes the higher purification to be happened. 


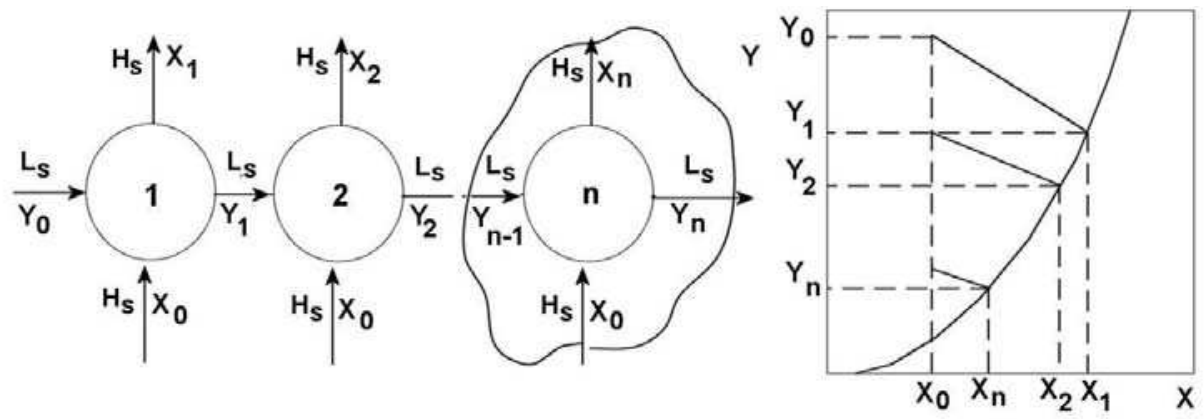

Fig. 12. A schematic of multistage crosscurrent contact and operating lines

\subsection{Cocurrent form of contact}

The flow direction of two phases is the same in cocurrent form of contact and the mass transfer driving force is decreased along the contactor from input to output section. A schematic of a contactor with cocurrent contact form is shown in Fig. 13. The mass balance equation in this case is written as

$$
\mathrm{L}_{\mathrm{s}} \mathrm{Y}_{1}+\mathrm{H}_{\mathrm{s}} \mathrm{X}_{1}=\mathrm{L}_{\mathrm{s}} \mathrm{Y}_{2}+\mathrm{H}_{\mathrm{s}} \mathrm{X}_{2}
$$

The operating line can be obtained by arranging this equation as

$$
-\frac{\mathrm{H}_{\mathrm{s}}}{\mathrm{L}_{\mathrm{s}}}=\frac{\mathrm{Y}_{2}-\mathrm{Y}_{1}}{\mathrm{X}_{2}-\mathrm{X}_{1}}
$$

The slope of operating line in this case is negative and the flow properties tend to approach the equilibrium conditions.
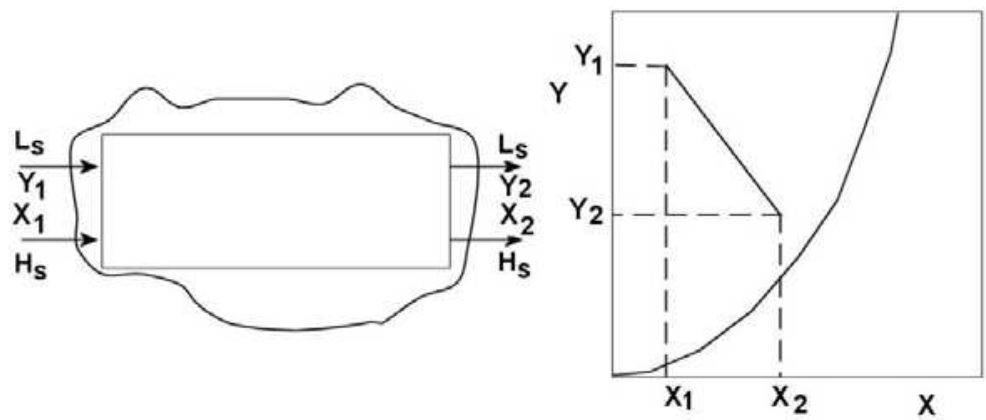

Fig. 13. A schematic of a contactor with cocurrent contact form in the case of absorption-like processes

\subsection{Countercurrent form of contact}

This type of contact has a good performance in comparison with other types. In this type two phases flow in opposite directions in the contactor. Therefore the driving force for mass transfer will be high enough to prepare a good purification condition in each stage. A 
schematic of this process is shown in Fig. 14 and the mass balance equation for the loop shown in this figure can be written as

$$
\mathrm{L}_{\mathrm{s}} \mathrm{Y}_{1}+\mathrm{H}_{\mathrm{s}} \mathrm{X}_{2}=\mathrm{L}_{\mathrm{s}} \mathrm{Y}_{2}+\mathrm{H}_{\mathrm{s}} \mathrm{X}_{1}
$$

Therefore the operating line in this case is written as follows

$$
\frac{\mathrm{H}_{\mathrm{s}}}{\mathrm{L}_{\mathrm{s}}}=\frac{\mathrm{Y}_{2}-\mathrm{Y}_{1}}{\mathrm{X}_{2}-\mathrm{X}_{1}}
$$

The slope of operating line in this case is positive as it is seen in Fig. 14.

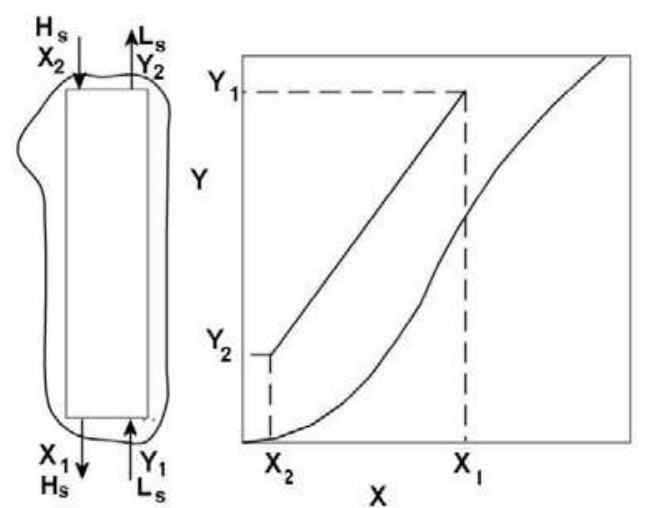

Fig. 14. A contactor with countercurrent flow in absorption-like process

\section{Staircase construction}

Calculating number of plates in a tray tower as a processing design parameter is investigated in this section. Two kinds of problems can be created relating with staircase construction. Sometimes a chemical engineer wants to design a tray tower and find the number of plates. In this case operating line or curve is known and number of theoretical plates can be calculated. But in number of cases a tray tower with fixed number of plates is existed and operation in tray tower should be arranged in such a way that we have fixed known number of plates. Therefore in this section two kinds of problems we are facing that are discussed and analyzed.

\subsection{Known operating conditions, unknown number of plates}

In the case of known operating conditions of temperature, pressure and compositions of the streams at two ends of the contactor a staircase construction can be used to find number of stages. Fig. 15 shows an absorption-like operation with known operating line and equilibrium curve. A staircase construction is shown in the figure from top to bottom or vice versa to find the number of theoretical stages as 6 .

\subsection{Known number of plates, unknown operating conditions}

Sometimes the purification process should be carried out in an available contactor with a known number of plates and the operating conditions are unknown. In this case the 

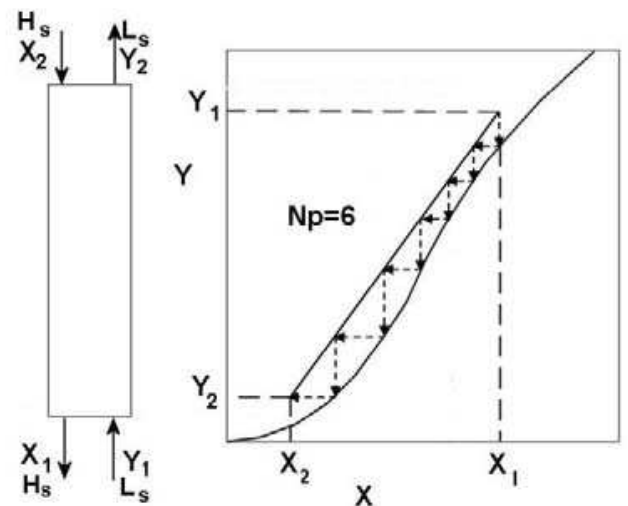

Fig. 15. A contactor with countercurrent flow form in the case of absorption-like process, known mole fractions for input and output streams and unknown number of stages

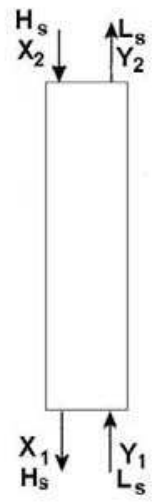

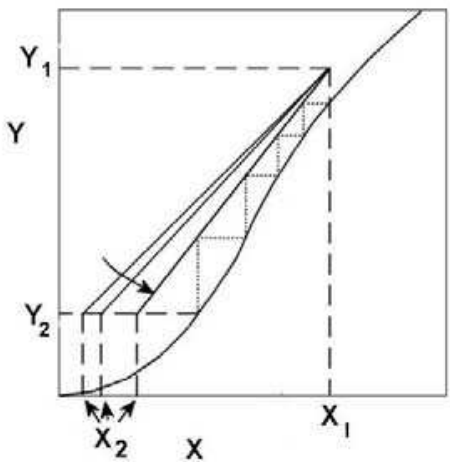

(a)

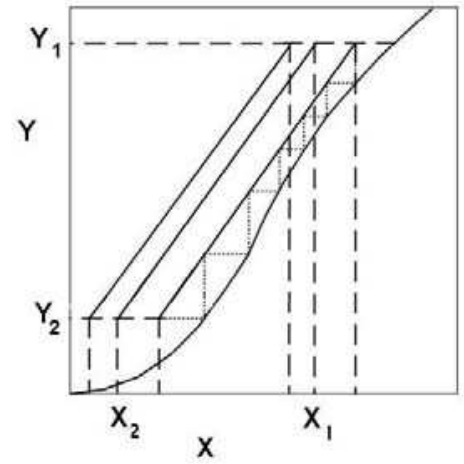

(b)

Fig. 16. An absorption-like process; (a) Known three mole ratios $\left(\mathrm{X}_{1}, \mathrm{Y}_{1}\right.$ and $\left.\mathrm{Y}_{2}\right)$ and five theoretical stages; (b) Known flow rates $\left(\mathrm{L}_{\mathrm{s}}, \mathrm{H}_{\mathrm{s}}\right)$, two mole ratios $\left(\mathrm{Y}_{1}, \mathrm{Y}_{2}\right)$ and six theoretical stages

calculations are performed using the trial and error method. Usually four parameters are necessary to fix the operating line of the process, but in the present case three of them are known with number of theoretical stages in the contactor. Four parameters necessary to fix the operating line may be the mole fractions of transferring component at top and bottom of the contactor in the heavy and light phases. Sometimes two mole fractions with known values of heavy and light phase flow rates are given. What important in these type of problems is that always trial and error method should be used to fix the conditions of the mass exchanger equipment.

In the usual cases the mole fraction of transferring component in the stream rich from it, stream necessary to carry out the purification and the desire stream after purification are known. Fig. 16a shows an absorption-like process that is expected to be carried out in a tray tower with five stages, countercurrently, with known mole ratios at section one $\left(\mathrm{X}_{1}, \mathrm{Y}_{1}\right)$ and 
$\mathrm{Y}_{2}$ at the section two. With known number of stages and using the known mole ratios and the method of trial and error, $X_{2}$ should be guessed and checked the number of stages. This computational procedure is continued to obtain the correct number of stages. Fig. 16b shows the case when two mole ratios of $Y_{1}$ and $Y_{2}$ and the flow rates (known slope of operating line) are known. In this case the operating line keeps sliding to get the correct number of stages.

\section{Different equilibrium diagrams and strategy of using difference points}

Depending on different separation processes and different contact forms of phases, different equilibrium diagrams seem to be useful. The formulations that are carried out on each process as the mass and heat balance equations, often force the process calculations to be done using different equilibrium diagrams. Part of calculations usually related to converting different types of equilibrium data to each other.

In distillation operation, the Hxy diagram (phase enthalpies versus transferable mole fraction) sometimes is used as equilibrium diagram. The liquid-liquid extraction and leaching process calculations can be carried out in triangular diagrams or rectangular diagrams e.g. Nxy diagrams in leaching ( $\mathrm{N}$ is in mass of solid matrix, marc per mass of liquid mixture; $\mathrm{x}$ and $\mathrm{y}$ are in mass of solute per mass of liquid mixture in heavy and light phases, respectively). The NXY diagram is used in liquid-liquid extraction when it assumes that a solvent is added to the feed solution and the transferable component is miscible in it $(\mathrm{N}$ is in mass of solvent added per mass of mixture with no solvent; $X$ and $Y$ are in mass of solute per mass of solvent free mixture in heavy and light phases, respectively). Fig. 17 shows different equilibrium diagrams which their tie lines are generated from usual equilibrium
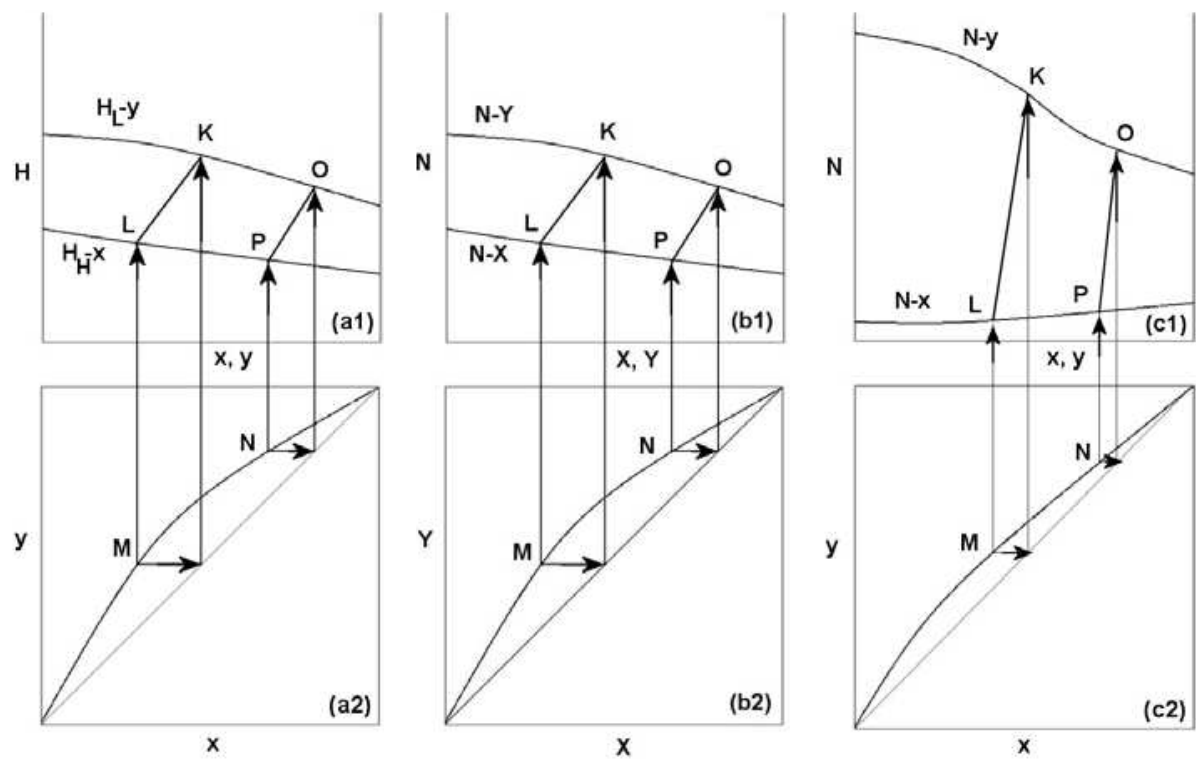

Fig. 17. Useful equilibrium diagrams; (a1, a2) Hxy diagram useful in distillation operation when using the Ponchon-Savarit method for binary systems; (b1, b2) NXY diagram used in liquid-liquid extraction; (c1, c2) Nxy diagram used in leaching operation 
curves. As it is shown each point on xy or $\mathrm{XY}$ diagrams (e.g. $\mathrm{M}$ or $\mathrm{N}$ ) can be converted to a tie line (KL or OP) on equilibrium curves laid on the top.

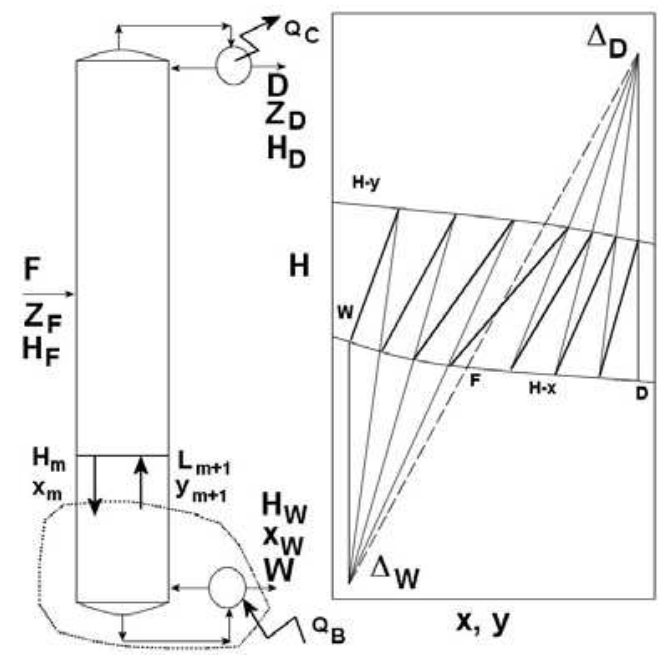

(a)

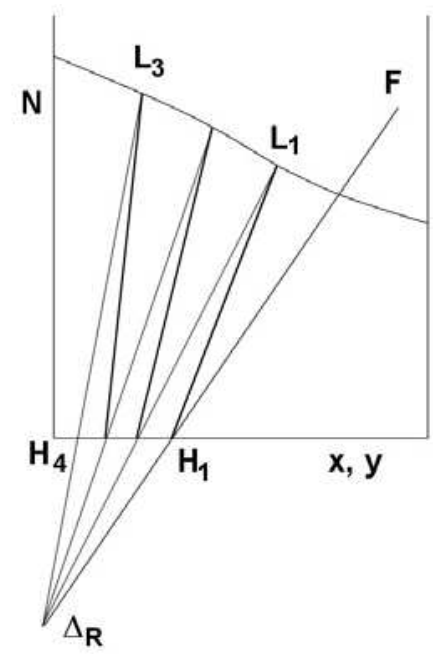

(b)

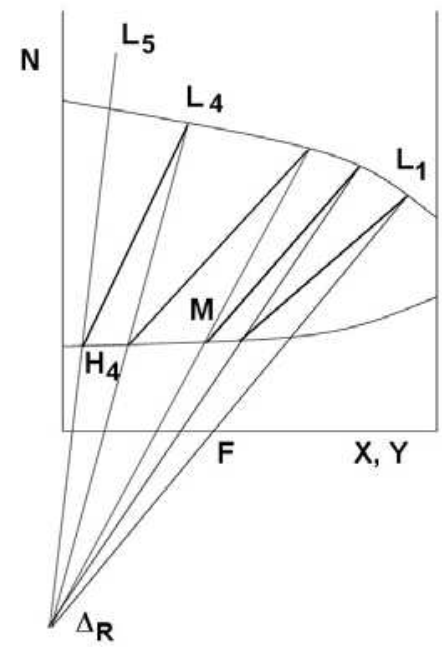

(c)

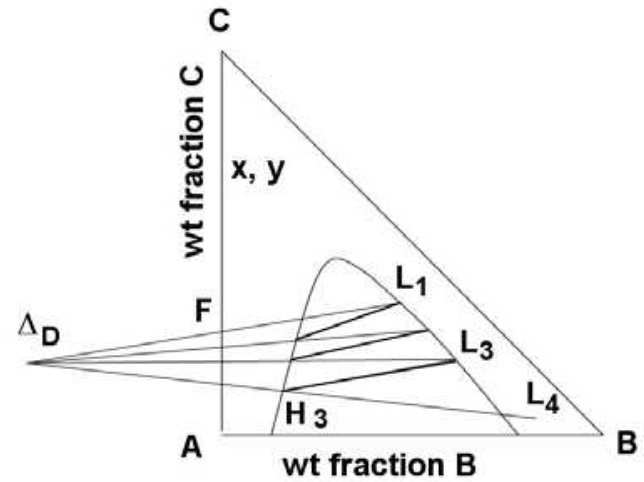

(d)

Fig. 18. Using difference point to carry out the processing calculations graphically (tie lines are shown as bold and other lines show the operating lines) (a) Distillation tower with 7 stages; (b) Leaching process with 3 stages; (c) Liquid-liquid extraction in 4 stage process (NXY equilibrium diagram); (d) Liquid-liquid extraction in 3 stage process (rectangular coordinates, $\mathrm{C}$ is the transferable component and $\mathrm{B}$ is the solvent used to separate $\mathrm{C}$ from its mixture with A) 
Strategy of using difference points is used in separation processes with countercurrent form of contact to analyze the operations graphically. This plan is produced from this reality that the difference between total flow rates or component flow rates of two phases passed next to each other is constant. It means that as it is shown in Fig. 18a in distillation process for the loop shown between stage $\mathrm{m}$ and the bottom product of the column, total mass balance and component mass balance equations can be written as

$$
\begin{aligned}
& \mathrm{H}_{\mathrm{m}}-\mathrm{L}_{\mathrm{m}+1}=\mathrm{W} \\
& \mathrm{H}_{\mathrm{m}} \mathrm{x}_{\mathrm{m}}-\mathrm{L}_{\mathrm{m}+1} \mathrm{y}_{\mathrm{m}+1}=\mathrm{Wx}_{\mathrm{W}}
\end{aligned}
$$

where $\mathrm{H}, \mathrm{L}$ and $\mathrm{W}$ are the flow rates of heavy phase, light phase and bottom product, respectively. The notations $\mathrm{x}$ and $\mathrm{y}$ are the mole fractions and $\mathrm{m}$ shows the stage number. As it is seen these equations can be written for all stages between feed tray and bottom of the tower and it means that the differences are constant. A similar equation can be added for heat balance and in that case the difference between energies is constant as well. The important subject is that in liquid-liquid extraction and leaching process when the contact form is countercurrent such equations can be developed and using a difference point to carry out the process calculations graphically seems to be necessary. Such points are brought in Fig. 18 for different processes of distillation, leaching and liquid-liquid extraction. The method that used to find number of stages graphically was described completely in ref. (Treybal, 1955).

\section{Packed bed height}

Differential form of contact is a usual method to contact phases in different separation processes. High surface area for contacting phases, less pressure drop, simplicity and low cost are the factors that cause this type of mass exchanger to be more useful. Height and number of transfer units are of important parameters that need to be calculated in packed bed contactors. During contact between phases along the height of the tower, concentration of separating component in two phases changes continuously and this type of mass transfer changes the rate of two streams as well. Sometimes transport of mass is occurred in the case of transfer into stagnant components e. g. absorption of ammonia from air with water, and sometimes it occurred as equimolar countertransfer e. g. in distillation process.

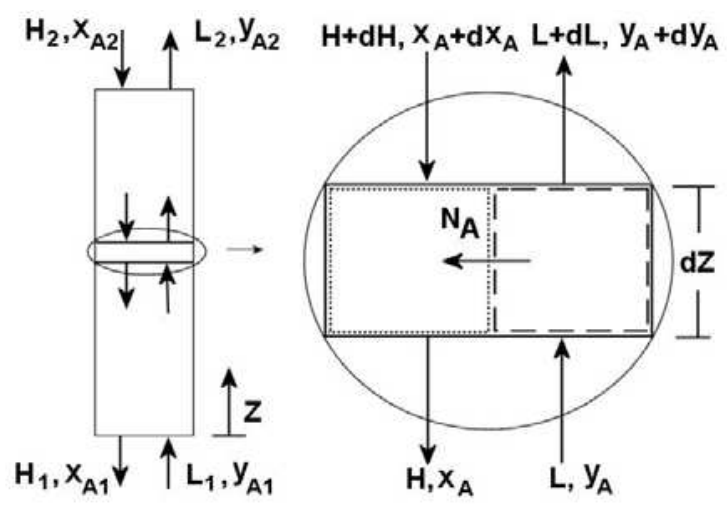

Fig. 19. A schematic of packed bed tower (left) and an element of tower in z-direction (right) 
A schematic of packed bed tower is shown in Fig. 19. The two phases of $\mathrm{L}$ and $\mathrm{H}$ flow inside the tower in countercurrent form. $\mathrm{L}$ and $\mathrm{H}$ show the flow rates as $\mathrm{kmol} /$ (time)(tower cross sectional area). The mass balance equation on one element, $\mathrm{dZ}$ from the tower as shown in RHS of Fig. 19 can be simplified as

$$
\mathrm{d}\left(\mathrm{Ly}_{\mathrm{A}}\right)=\mathrm{d}\left(\mathrm{Hx}_{\mathrm{A}}\right)
$$

The mass balance equation on phase- $\mathrm{L}$ can be written as well

$$
-\mathrm{N}_{\mathrm{A}} \mathrm{dS}=\mathrm{d}\left(\mathrm{Ly}_{\mathrm{A}}\right)
$$

where dS is the total surface area that mass can be transferred from it, in dZ element, per tower cross sectional area.

In packed beds $\mathrm{dS}$ can be calculated from its relation with packing specific area, a and $\mathrm{dZ}$ as

$$
\mathrm{dS}=\mathrm{adZ}
$$

The packing specific area is defined as total surface area of packing per volume of tower. A proper relation can be written for flux of component A e.g. in the case of equimolar countertransfer in low mass transfer rate based on overall mass transfer coefficient in light phase the following relation can be written

$$
\mathrm{N}_{\mathrm{A}}=\mathrm{K}_{\mathrm{y}}^{\prime}\left(\mathrm{y}_{\mathrm{A}}-\mathrm{y}_{\mathrm{A}}^{*}\right)
$$

The flow rate $\mathrm{L}$ is assumed to be constant in the case of equimolar countertransfer. Replacing dS from equation (30) and $\mathrm{N}_{\mathrm{A}}$ from equation (31) into equation (29) and considering $\mathrm{L}$ as a constant

$$
-\mathrm{K}_{\mathrm{y}}^{\prime}\left(\mathrm{y}_{\mathrm{A}}-\mathrm{y}_{\mathrm{A}}^{*}\right) \mathrm{adZ}=\mathrm{Ldy} \mathrm{A}_{\mathrm{A}}
$$

By separating the variables and integration the following equation is obtained

$$
\mathrm{Z}=\int_{0}^{\mathrm{Z}} \mathrm{dZ}=\int_{\mathrm{y}_{\mathrm{A} 1}}^{\mathrm{y}_{\mathrm{A} 2}} \frac{\mathrm{L}}{\mathrm{K}_{\mathrm{y}}^{\prime} \mathrm{a}} \frac{\mathrm{dy}_{\mathrm{A}}}{\left(\mathrm{y}_{\mathrm{A}}^{*}-\mathrm{y}_{\mathrm{A}}\right)}
$$

If $\mathrm{H}_{\mathrm{OL}}=\mathrm{L} / \mathrm{K}_{\mathrm{y}}^{\prime} \mathrm{a}$ and is defined as height of the transfer units for the overall mass transfer coefficient and is assumed to be constant, the following equation is obtained from equation (33)

$$
\mathrm{Z}=\mathrm{H}_{\mathrm{OL}} \int_{\mathrm{y}_{\mathrm{A} 1}}^{\mathrm{y}_{\mathrm{A} 2}} \frac{\mathrm{dy}_{\mathrm{A}}}{\mathrm{y}_{\mathrm{A}}^{*}-\mathrm{y}_{\mathrm{A}}}
$$

The value of integral is defined as the number of transfer units, $\mathrm{NOL}_{\mathrm{OL}}$ as

$$
\mathrm{N}_{\mathrm{OL}}=\int_{\mathrm{y}_{\mathrm{A} 1}}^{\mathrm{y}_{\mathrm{A} 2}} \frac{\mathrm{dy}_{\mathrm{A}}}{\mathrm{y}_{\mathrm{A}}^{*}-\mathrm{y}_{\mathrm{A}}}
$$


In the case when transfer of component through stagnant components takes place and for low mass transfer rate, the K coefficients should be used to define flux relation and equation (31) should be replaced with

$$
\mathrm{N}_{\mathrm{A}}=\mathrm{K}_{\mathrm{y}}\left(\mathrm{y}_{\mathrm{A}}-\mathrm{y}_{\mathrm{A}}^{*}\right)=\frac{\mathrm{K}_{\mathrm{y}}^{\prime}}{\left(1-\mathrm{y}_{\mathrm{A}}\right)_{*} \mathrm{M}}\left(\mathrm{y}_{\mathrm{A}}-\mathrm{y}_{\mathrm{A}}^{*}\right)
$$

where

$$
\left.\left(1-\mathrm{y}_{\mathrm{A}}\right)\right)_{\mathrm{M}}=\frac{\left(1-\mathrm{y}_{\mathrm{A}}\right)-\left(1-\mathrm{y}_{\mathrm{A}}^{*}\right)}{\ln \frac{1-\mathrm{y}_{\mathrm{A}}}{1-\mathrm{y}_{\mathrm{A}}^{*}}}
$$

Indeed when component A transfers through stagnant components, e.g. absorbing ammonia from air using water, flow rate L cannot be assumed as a constant and it can be formulated as

$$
\mathrm{L}=\frac{\mathrm{L}_{\mathrm{s}}}{1-\mathrm{y}_{\mathrm{A}}}
$$

where $L_{s}$ is part of the light phase flow rate that is nontransferable or stagnant. Replacing new values for $\mathrm{N}_{\mathrm{A}}$ and L from equations (36) and (38), respectively, into equation (29), other relations are produced for height of packed bed and number of transfer units.

When the rate of mass transfer is high, using $\mathrm{F}$ coefficient as mass transfer coefficient is usual and other form of definition of $\mathrm{N}_{\mathrm{A}}$ is needed. The governing equations in this case have been presented in ref. (Hines \& Maddox, 1985).

\section{Conclusion}

In the present chapter it tried to figure out a mass transfer sense related to more useful purification processes in chemical industries. A common sense in different processes was obtained based on classifying all separation processes into two broad categories of absorption-like and desorption-like processes. This classification can help the reader to get a similar sense when see separation processes individually. Referring denser phase as a heavy phase in comparison with the second phase causes the processing calculations to be simplified and categorized easily. The basic concepts of mass transfer were used to describe what happened in the interface between two phases and a brief discussion on the phase equilibria was used to generate equilibrium curves.

Also it tried to bring a good summary on significant processing calculations in different contact forms of phases and finally the calculations on two mass exchangers of tray towers and packed-bed columns were presented briefly.

\section{References}

Geankoplis, C. J.; (2003). Transport Processes And Separation Process Principles, New Jersey, Prentice Hall PTR.

Henley, E. J.; \& Seader, J. D. (1981). Equilibrium-Stage Separation Operations In Chemical Engineering, John Wiley \& Sons. 
Hines, A. L.; \& Maddox, R. N. (1985). Mass Transfer Fundamentals and Applications, Prentice Hall.

Khoury, F. M.; (1995). Predicting The Performance Of Multistage Separation Processes, Houston, Gulf Publishing Company.

Luikov, A. V.; (1980). Heat and Mass Transfer, Moscow, Mir Publisher.

McCabe, W. L.; Smith, J. C., \& Harriott, P. (1956). Unit Operations Of Chemical Engineering, McGraw Hill.

Pavlov, K. F.; Romankov, P. G., \& Noskov, A. A. (1979). Examples And Problems To The Course Of Unit Operations Of Chemical Engineering, Moscow, Mir Publisher.

Poling, B. E.; Prausnitz, J. M., \& O'Connell, J. P. (2001). The Properties Of Gases And Liquids, McGraw Hill.

Rudzinski, W.; Steele, W. A., \& Zgrablich, G. (1997). Equilibria And Dynamics Of Gas Adsorption On Heterogeneous Solid Surfaces, Elsevier.

Treybal, R. E.; (1955). Mass Transfer Operations, McGraw Hill. 


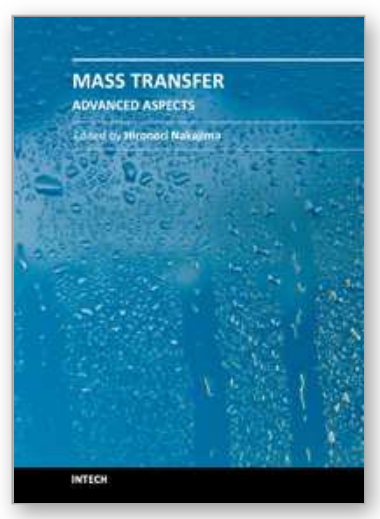

\author{
Mass Transfer - Advanced Aspects \\ Edited by Dr. Hironori Nakajima
}

ISBN 978-953-307-636-2

Hard cover, 824 pages

Publisher InTech

Published online 07, July, 2011

Published in print edition July, 2011

Our knowledge of mass transfer processes has been extended and applied to various fields of science and engineering including industrial and manufacturing processes in recent years. Since mass transfer is a primordial phenomenon, it plays a key role in the scientific researches and fields of mechanical, energy, environmental, materials, bio, and chemical engineering. In this book, energetic authors provide present advances in scientific findings and technologies, and develop new theoretical models concerning mass transfer. This book brings valuable references for researchers and engineers working in the variety of mass transfer sciences and related fields. Since the constitutive topics cover the advances in broad research areas, the topics will be mutually stimulus and informative to the researchers and engineers in different areas.

\title{
How to reference
}

In order to correctly reference this scholarly work, feel free to copy and paste the following:

Behnam Khoshandam (2011). Mass Transfer - The Skeleton of Purification Processes, Mass Transfer Advanced Aspects, Dr. Hironori Nakajima (Ed.), ISBN: 978-953-307-636-2, InTech, Available from: http://www.intechopen.com/books/mass-transfer-advanced-aspects/mass-transfer-the-skeleton-of-purificationprocesses

\section{INTECH}

open science | open minds

\section{InTech Europe}

University Campus STeP Ri Slavka Krautzeka 83/A 51000 Rijeka, Croatia Phone: +385 (51) 770447 Fax: +385 (51) 686166 www.intechopen.com

\section{InTech China}

Unit 405, Office Block, Hotel Equatorial Shanghai

No.65, Yan An Road (West), Shanghai, 200040, China

中国上海市延安西路65号上海国际贵都大饭店办公楼 405 单元

Phone: +86-21-62489820

Fax: +86-21-62489821 
(C) 2011 The Author(s). Licensee IntechOpen. This is an open access article distributed under the terms of the Creative Commons Attribution 3.0 License, which permits unrestricted use, distribution, and reproduction in any medium, provided the original work is properly cited. 